Check for updates

Cite this: RSC Adv., 2017, 7, 40480

\section{Evaluation of 4-alkoxy-4'-nitrobiphenyl liquid crystals for use in next generation scattering LCDs $\dagger$}

\begin{abstract}
Richard J. Mandle, (D) Stephen J. Cowling and John W. Goodby
We have prepared nine members of the 4-alkoxy-4'-nitrobiphenyl family of liquid crystals and evaluated their thermal behaviour by a combination of polarised optical microscopy, differential scanning calorimetry and small angle X-ray scattering, as well as in single pixel scattering devices for use in backlight free liquid crystal displays (LCDs). Whereas homologues with shorter terminal aliphatic chains are nematogenic, those with longer aliphatic chain lengths exhibit an additional smectic A phase, identified as the subtype $\mathrm{SmA}_{D}$ by SAXS with all materials having a $D / L$ ratio (smectic layer spacing divided by molecular length) of 1.4 . When doped with $0.1 \mathrm{wt} \%$ hexadecyltrimethylammonium perchlorate we observed that the $\mathrm{SmA}_{D}$ phase of compound 9 could be switched with a relatively low voltage (58 $V_{R M S}$, roughly half that required for the analogous nitrile). This apparent reduction in threshold voltage, which occurs as a consequence of switching from a nitrile- to a nitro- group, provides a new impetus to study alternative polar terminal groups when designing host materials for smectic A scattering devices.
\end{abstract}

Received 20th June 2017 Accepted 14th August 2017

DOI: $10.1039 / \mathrm{c} 7 \mathrm{ra06886g}$

rsc.li/rsc-advances bulky groups does not reduce the driving voltage of the resulting smectic A phase and so there is still a need for materials with superior behaviour under applied fields. Our motivation was to

Smectic A scattering devices are a broad class of liquid crystal displays that utilise the lamellar smectic A phase as opposed to the nematic based display technology currently in use. Scattering devices offer advantages over nematic based displays; as the device scatters incident light a backlight is not required and thus power consumption is low, and as both the 'on' and 'off' states are bistable the display is therefore persistent. ${ }^{1-8}$ In addition to finding use in displays this technology could also be used in smart windows, ${ }^{1}$ e-paper, ${ }^{9}$ and so on. Broadly speaking, this type of scattering device works by having a small quantity $(\sim 0.1 \mathrm{wt} \%)$ of a soluble ionic additive in a smectic A host (ideally with a wide temperature range). A high frequency $(>1 \mathrm{kHz})$ AC electric field is then applied with sufficient amplitude to align the liquid crystalline materials with the field to give a clear state; however if a low frequency $(<50 \mathrm{~Hz})$ AC electric field is applied the movement of the ionic additive disrupts the smectic layers leading to a scattering texture.

The exploitation of such devices is stymied by a lack of suitable host materials, with existing SmA materials, such as 4-undecyloxy-4'-cyanobiphenyl (110CB, Fig. 1), requiring large driving voltages to switch $(c a .100 \mathrm{~V}) .{ }^{\mathbf{1 1 , 1 2}}$ It has been demonstrated previously that positioning a bulky groups, ${ }^{\mathbf{1 1 , 1 3 - 2 1}}$ or halogens ${ }^{22,23}$ at the end of one (or both) terminal chains can lead to significant reductions in melting points with only minimal change in the clearing point. However, the incorporation of

Department of Chemistry, University of York, UK. E-mail: richard.mandle@york.ac.uk $\dagger$ Electronic supplementary information (ESI) available. See DOI: 10.1039/c7ra06886g

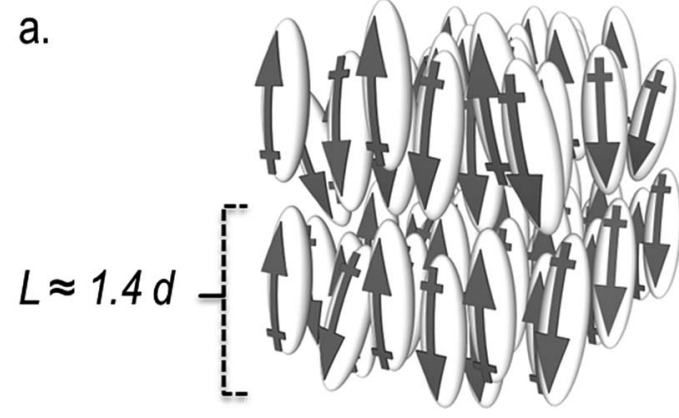

b.

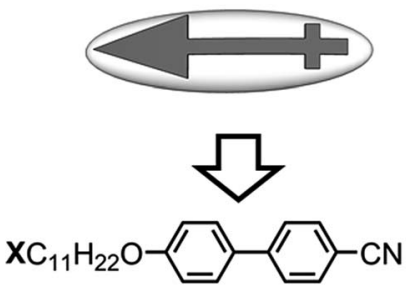
110CB:$$
\mathbf{X}=-\mathrm{H}
$$$$
\mathbf{X}=-\mathrm{C}\left(\mathrm{CH}_{3}\right)_{3}
$$
Cr 71.5 SmA 87.5 Iso
tBu110CB
$\begin{array}{lll}\text { tBu110CB } & \mathbf{X}=-\mathrm{C}\left(\mathrm{CH}_{3}\right)_{3} & \mathrm{Cr} 54.9 \mathrm{SmA}_{\mathrm{D}} 83.3 \text { Iso } \\ \text { SiOSi110CB } & \mathbf{X}=-\mathrm{Si}\left(\mathrm{CH}_{3}\right)_{2} \mathrm{OSi}\left(\mathrm{CH}_{3}\right)_{3} \mathrm{Cr} 37.7 \mathrm{SmA}_{\mathrm{D}} 73.7 \text { Iso }\end{array}$
Cr 54.9 SmA 83.3 Iso

Fig. 1 (a) Cartoon depicting of the molecular organisation within the interdigitated smectic $A$ phase $\left(\mathrm{SmA}_{D}\right)$ where the layer spacing is approximately 1.4 times the molecular length. ${ }^{10}$ (b) The molecular structures and transition temperatures of $110 C B, t B u 110 C B$ and SiOSiO11OCB (taken from ref. 11). 
explore if polar terminal groups other than cyano could (a) lead to wide temperature range smectic A phases and (b) offer reductions in the driving voltage, relative to nitriles. In this present work we report on the synthesis and characterisation of nine members of the 4 -alkoxy- $4^{\prime}$-nitrobiphenyl series of materials.

\section{Experimental}

4-Hydroxy-4'-nitrobiphenyl was prepared as described previously, ${ }^{24}$ in accordance with the method of Jones. ${ }^{25}$ Bromoalkanes were obtained from commercial suppliers and used without further purification. Solvents were purchased from Fisher scientific UK. Full experimental details, including details of instrumentation used, are given in the $\mathrm{ESI} \dagger$ to this article. Computational chemistry was performed in Gaussian G09 rev d01, ${ }^{26}$ selected output files were rendered using Qutemol. ${ }^{27}$ For the probe of conformational space a Python script was used to generate output files with the required dihedral angles, the resulting Gaussian output files were read by a Matlab script which extracted molecular lengths and energies.

\section{Results and discussion}

The transition temperatures of the 4 -alkoxy- $4^{\prime}$-nitrobiphenyl series were determined via a combination of polarised optical microscopy (POM), differential scanning calorimetry (DSC) and - for materials exhibiting smectic mesophases - small angle Xray scattering (SAXS). Details of the instrumentation used are given in the ESI $\dagger$ to this article.

Transition temperatures and associated enthalpies as determined by DSC are presented in Table 1 . Where literature data exists we find our transition temperatures to be in good agreement: cpd $3=74-75{ }^{\circ} \mathrm{C} ;{ }^{28}$ cpd 4 , MP $=81.0{ }^{\circ} \mathrm{C}^{29}$ The assignment of the nematic and smectic A phases was trivial based on microscopy (Fig. 2), subsequent SAXS data confirms these assignments and demonstrates the SmA phase to be of the

Table 1 Transition temperatures $\left({ }^{\circ} \mathrm{C}\right)$ and associated enthalpies [ $\mathrm{kJ}$ $\mathrm{mol}^{-1}$ ] for the 4-alkoxy-4'-nitrobiphenyl series (compounds 1-9), as determined via DSC at a heat/cool rate of $10^{\circ} \mathrm{C} \mathrm{min}^{-1} . \mathrm{Cr}=$ Crystalline solid, $\mathrm{SmA}_{D}=$ smectic $\mathrm{A}$ phase $(\mathrm{SmA})$ with interdigitated layers $(D), \mathrm{N}=$ nematic mesophase, Iso = isotropic liquid

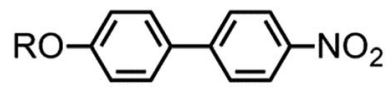

\begin{tabular}{|c|c|c|c|c|c|c|c|c|}
\hline No. & $\mathrm{R}$ & $\mathrm{Cr}$ & & \multicolumn{2}{|c|}{$\mathrm{SmA}_{D}$} & $\mathrm{~N}$ & & \\
\hline 1 & $\mathrm{C}_{3} \mathrm{H}_{7}$ & & $74.1[26.7]$ & - & - & - & - & \\
\hline 2 & $\mathrm{C}_{4} \mathrm{H}_{9}$ & & $80.6[24.3]$ & 一 & - & 一 & - & \\
\hline 3 & $\mathrm{C}_{5} \mathrm{H}_{11}$ & & $54.7[27.5]$ & - & - & - & - & \\
\hline 4 & $\mathrm{C}_{6} \mathrm{H}_{13}$ & & $67.6[24.6]$ & 一 & - & (O & $35.0)[0.2]$ & \\
\hline 5 & $\mathrm{C}_{7} \mathrm{H}_{15}$ & & $37.5[24.6]$ & $(8$ & $33.5)[0.1]$ & 0 & $42.5[0.3]$ & \\
\hline 6 & $\mathrm{C}_{8} \mathrm{H}_{17}$ & & $49.3[31.5]$ & 0 & $50.2[0.1]$ & O & $52.6[0.3]$ & \\
\hline 7 & $\mathrm{C}_{9} \mathrm{H}_{19}$ & & $56.5[38.3]$ & C & $56.7[1.4]$ & 一 & - & \\
\hline 8 & $\mathrm{C}_{10} \mathrm{H}_{21}$ & & $70.3[42.2]$ & ( & $63.8)[2.0]$ & - & - & \\
\hline 9 & $\mathrm{C}_{11} \mathrm{H}_{23}$ & & $56.6[37.0]$ & & $66.4[2.0]$ & - & - & \\
\hline
\end{tabular}
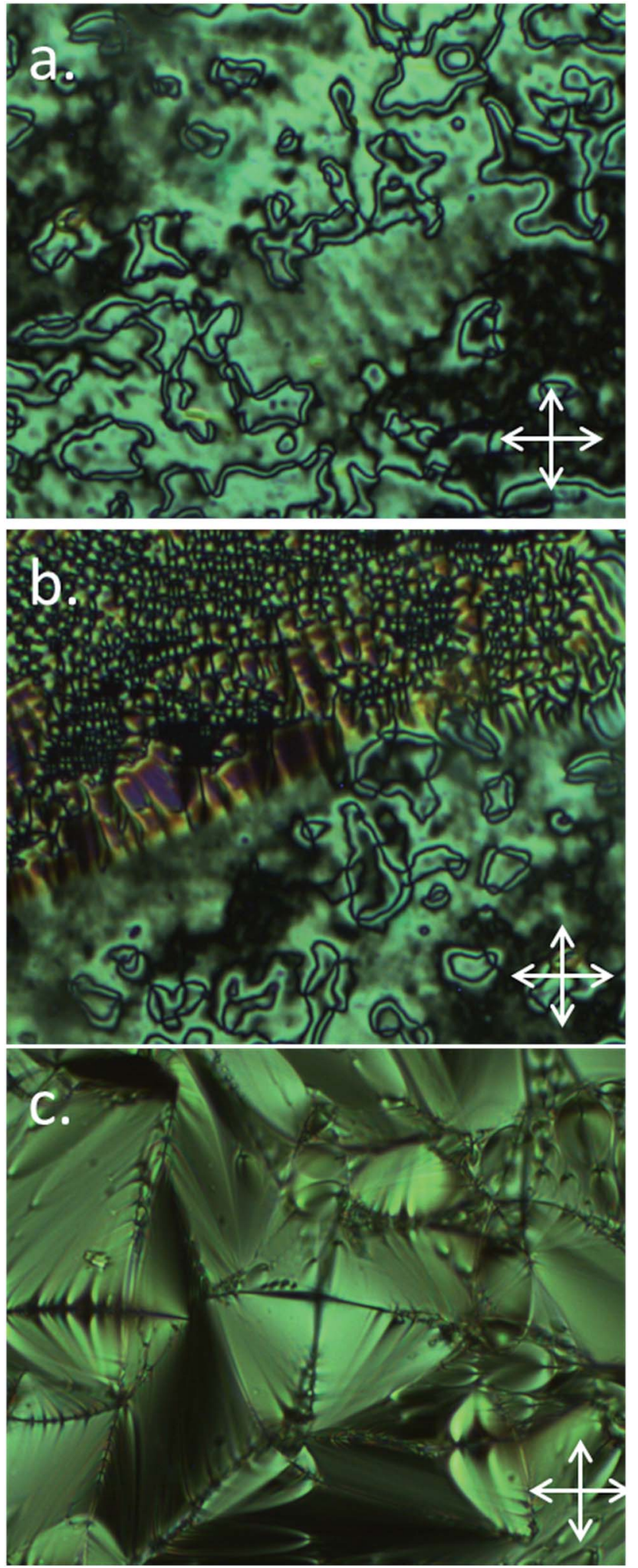

Fig. 2 Photomicrographs $(\times 100)$ of $(a)$ the nematic phase of compound 5 at $38{ }^{\circ} \mathrm{C}$, (b) compound 5 cooled to the N-SmA phase transition at $33.5^{\circ} \mathrm{C}$, (c) focal-conic and parabolic defect textures exhibited by the smectic A phase of 9 at a temperature of $65^{\circ} \mathrm{C}$. 
subtype $\mathrm{SmA}_{D}$ (i.e. an interdigitated smectic A phase), and this will be discussed shortly.

For any given 4-alkoxy-4'-nitrobiphenyl the clearing point (either N-Iso or SmA-Iso) and SmA-N transition temperature (if present) occur at a lower temperature than for the corresponding nOCB material (Table 2).

The end-to-end molecular lengths of compounds 6-9 were calculated at the B3LYP/6-311G(d) level of DFT assuming a rigid, all trans terminal chain. Despite being standard practice this assumption of an all trans geometry is perhaps unrealistic as it ignores the flexibility of the terminal chain, which at the temperatures in question will lead to significant population of conformers with gauche torsional angles. To illustrate this point we performed fully relaxed scans on each of the flexible torsions within the terminal chain of compound $\mathbf{6}$, allowing 3 -fold rotation about each (i.e. trans, -gauche, +gauche). The 3-fold rotation about each of the 6 torsions leads to a large number of conformers $\left(3^{6}=729\right)$ and so this calculation was performed using a semi-empirical method (AM1) rather than using DFT. We then obtain a molecular length for each conformer as well as a Boltzmann population allowing us to obtain a probability weighted average molecular length of $18.4 \AA$ for compound $\mathbf{6}$, significantly smaller than that of the all trans form (Fig. 3). It must be noted however that as this value is obtained for an isolated molecule (and therefore will exhibit some difference to values obtained in a condensed phase of matter) and dispersion interactions are neglected this analysis will likely underestimate the population of the all trans form and therefore the molecular length, however it does serve to highlight the flexible nature of the terminal chain and the impact this has on the molecular length.

We next subjected compounds 6-9 to study by SAXS; the two dimensional scattering patterns (see Fig. 4) were radially averaged $\left(0.05^{\circ}\right.$ step size) to give plots of intensity versus two theta for each temperature studied; the $d$-spacing values of the small angle scattering peak were obtained by fitting the raw scattered data with a 3-term Gaussian function (see ESI for an example of fitted data in Fig. ESI-1†). The layer spacing of the smectic A phase of compounds 6-9 was found to be effectively

Table 2 The transition temperatures $\left({ }^{\circ} \mathrm{C}\right)$ of the nOCB compounds; values were taken from ref. 30-32

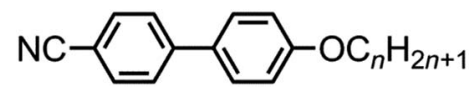

\begin{tabular}{|c|c|c|c|c|c|c|c|c|}
\hline \multirow[b]{2}{*}{$30 \mathrm{OCB}$} & \multirow{2}{*}{$\begin{array}{l}n= \\
3\end{array}$} & \multicolumn{2}{|l|}{$\mathrm{Cr}$} & \multicolumn{2}{|c|}{$\mathrm{SmA}_{D}$} & \multicolumn{2}{|l|}{$\mathrm{N}$} & \multirow{2}{*}{ Iso } \\
\hline & & 0 & 44.9 & - & - & 10 & $40.0)$ & \\
\hline 4OCB & 4 & 0 & 78.0 & - & - & $(0$ & 75.5) & \\
\hline $50 C B$ & 5 & 0 & 48.0 & - & - & 0 & 68.0 & 0 \\
\hline $60 C B$ & 6 & 0 & 57.0 & - & - & 0 & 75.5 & 0 \\
\hline $70 C B$ & 7 & 0 & 54.0 & - & - & 0 & 74.0 & 0 \\
\hline $80 C B$ & 8 & $\bullet$ & 54.5 & 0 & 67.2 & 0 & 81.0 & 0 \\
\hline 9OCB & 9 & 0 & 61.3 & 0 & 77.9 & 0 & 80.0 & \\
\hline 10OCB & 10 & 0 & 59.5 & 0 & 83.9 & - & - & \\
\hline $110 \mathrm{OB}$ & 11 & 0 & 71.5 & 0 & 87.5 & - & - & 0 \\
\hline
\end{tabular}
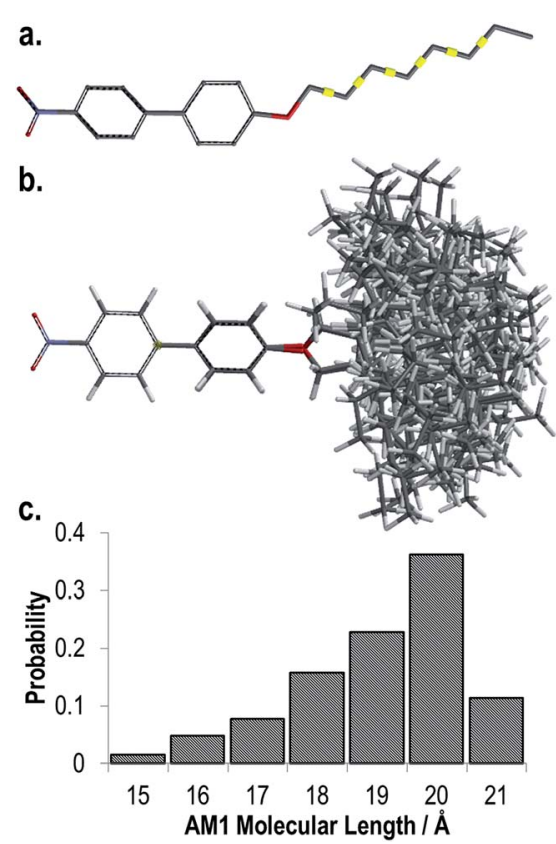

Fig. 3 (a) Molecular structure of the all trans ground state of 6; yellow bands indicate the bonds allowed to undergo 3 -fold rotation during the conformational study, (b) overlaid geometries of the conformers within $20 \mathrm{~kJ} \mathrm{~mol}^{-1}$ of the all trans ground state; (c) histogram plot (bin size $1 \AA$ ) showing the distribution of molecular lengths obtained from AM1 calculations.

temperature invariant with only a fractional increase over the temperature range in question; for compound $\mathbf{9}$ an increase in the $D / L$ ratio of $0.09 \%$ was observed over the temperature range studied (Fig. 4). Tabulated layer spacings, molecular lengths and $D / L$ ratios obtained using the all trans molecular length are given in Table 3.

The $D / L$ ratio is pertinent for the determination of the subtype of smectic A phase: a monolayer phase $\left(\mathrm{SmA}_{1}\right)$ will have a value close to 1 ; a bilayer phase $\left(\mathrm{SmA}_{2}\right)$ a value close to 2 ; while an interdigitated smectic A phase $\left(\mathrm{SmA}_{D}\right)$ has a value intermediate between these two extremes. ${ }^{10}$ Measurement of the $D / L$ ratio for 6-9 demonstrates that the smectic phase is of the subtype $\mathrm{SmA}_{D}$, with little variation in this value as a function of either temperature or chain length. Using the Boltzmann weighted molecular length of 6 we obtain a much larger $D / L$ ratio of $\sim 1.57$, however as mentioned previously this methodology likely underestimates the molecular length as a consequence of underestimating the population of the dominant all trans conformer.

Previously we demonstrated that despite the large dipole moment and highly anisotropic polarisability the 4-alkoxy-4'nitrobiphenyls exhibit anomalously low dielectric anisotropy due to the increased tendency to form antiparallel correlated pairs; ${ }^{24}$ For 4 and $6 \Delta \varepsilon \approx 8.7$ whereas for the analogous nitrile materials (6OCB and 8OCB, Table 2 ) $\Delta \varepsilon \approx 10.8$. As the dielectric anisotropy depends primarily on the molecular dipole moment, polarisability and order parameter it is a fair assumption that the dipole moment of compounds 7-9 will be comparable in magnitude to 4 and 6 . Using these values of dielectric 

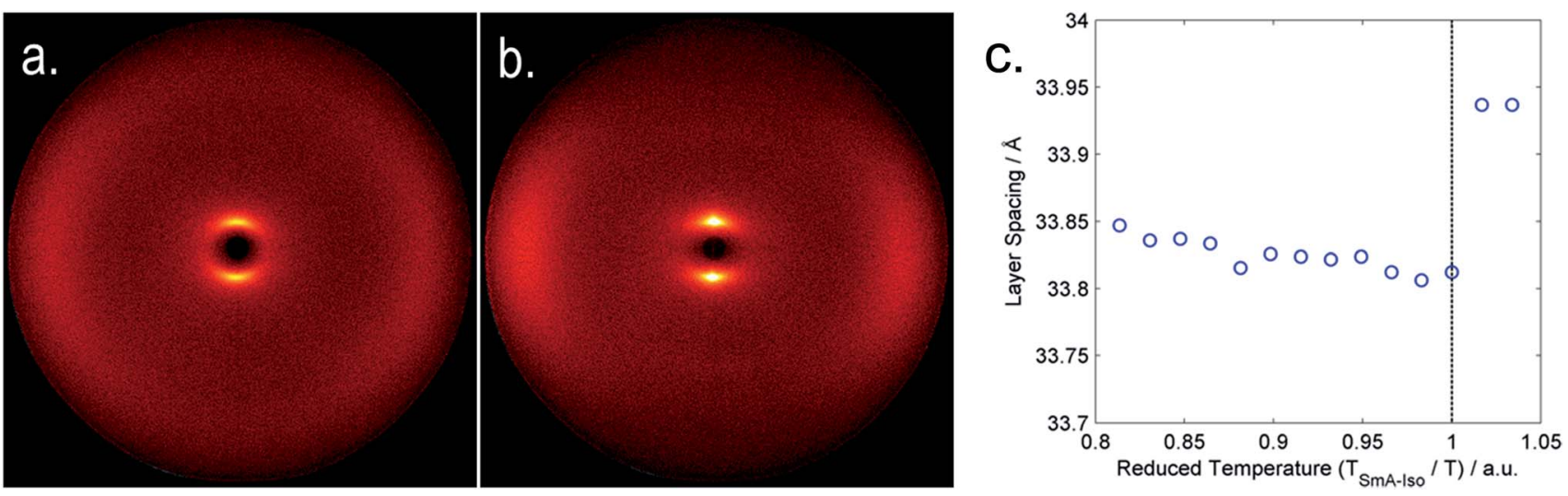

Fig. 4 (a) 2D SAXS pattern for the nematic phase of 6 at $51^{\circ} \mathrm{C}$, (b) 2D SAXS pattern for the smectic A phase of 6 at $45^{\circ} \mathrm{C}$, (c) plot of the smectic layer spacing as a function of reduced temperature for compound 9 , where the dashed line corresponds to the clearing point. Additional 2D SAXS patterns are presented in the ESI† to this article.

Table 3 The average smectic layer spacing $\left(D_{\text {mean }}, \AA\right)$, molecular length obtained on geometry optimised at the DFT(B3LYP/6-311G(d)) level $(L, \AA)$, and the corresponding $D / L$ ratio for compounds $6-9$ obtained from small angle $X$-ray scattering experiments as described in the text

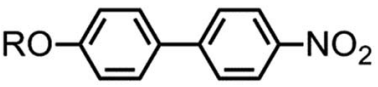

\begin{tabular}{lllll}
\hline No. & $\mathrm{R}$ & $D_{\text {mean }} / \AA$ & $L_{\mathrm{DFT}} / \AA$ & $D / L$ ratio \\
\hline 6 & $-\mathrm{C}_{8} \mathrm{H}_{17}$ & 28.94 & 20.44 & 1.42 \\
7 & $-\mathrm{C}_{9} \mathrm{H}_{19}$ & 30.64 & 21.63 & 1.42 \\
8 & $-\mathrm{C}_{10} \mathrm{H}_{21}$ & 32.40 & 22.99 & 1.41 \\
9 & $-\mathrm{C}_{11} \mathrm{H}_{23}$ & 33.82 & 24.19 & 1.40
\end{tabular}

anisotropy and finding solutions to the Maier-Meier equations using dipole/polarisability values obtained from $a b$ initio calculations allowed us to demonstrate that 4-alkoxy-4'-nitrobiphenyls exhibit a higher degree of pairing than their cyano analogues. ${ }^{24}$ The relatively low positive dielectric anisotropy is prohibitive to any potential use in nematic based devices, however, as compound 9 exhibits an enantiotropic smectic A phase and has a reasonably low melting point we decided to assess the suitability of this material for use in smectic A scattering devices. A mixture of compound 9 doped with $0.1 \mathrm{wt} \%$ of hexadecyltrimethylammonium perchlorate was prepared and the sample filled into a glass cell with ITO electrodes (spacing $\approx$ $50 \mu \mathrm{m}$, cells supplied by Halation, Fig. 5a).

The mixture (compound 9 with 0.1 wt\% hexadecyltrimethylammonium perchlorate) had a clearing point of $62.9{ }^{\circ} \mathrm{C}$, i.e. $3.5{ }^{\circ} \mathrm{C}$ lower than neat 9 , as determined by microscopy. Application of electric fields was performed at a temperature of $55{ }^{\circ} \mathrm{C}$. Using a square waveform the voltage required to transform the focal-conic texture into the scattering state was $58 \mathrm{~V}_{\mathrm{RMS}}$, with a frequency of $2 \mathrm{~Hz}$. With amplitude of $58 \mathrm{~V}$ the scattering state could be transformed to a clear state by increasing the frequency to $20 \mathrm{kHz}$. Both the clear and scattering states appear to be bistable as would be expected (photomicrographs of the switching process are given in Fig. 5). We found the voltage required to switch the smectic A phase of 9 is roughly half of what was required by us to switch 4-alkoxy-4'cyanobiphenyls in a previous publication. ${ }^{\mathbf{1 1}}$ The smectic A host

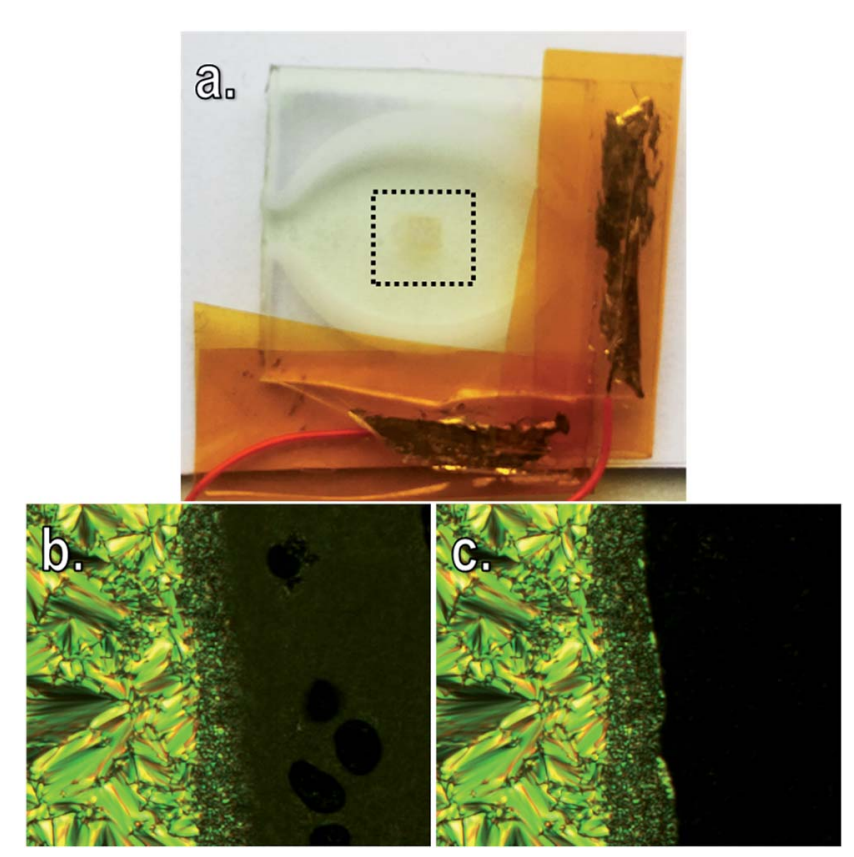

Fig. 5 Compound 9 doped with 0.1 wt\% hexadecyltrimethylammonium perchlorate in the smectic $\mathrm{A}$ phase at $55^{\circ} \mathrm{C}$ and confined in $50 \mu \mathrm{m}$ cells with ITO electrodes: (a) photograph of the cell filled with perchlorate doped compound 9, with the dashed box showing the location of the ITO electrodes. (b) Photomicrograph $(\times 100)$ of the virginal texture of the SmA phase (left) and the scattering texture (right) induced by application of an electric field $\left(58 \mathrm{~V}_{\mathrm{RMS}}, 2 \mathrm{~Hz}\right.$, square waveform); (c) photomicrograph $(\times 100)$ of the unchanged virginal texture (left) and the clear state (right) induced by application of an electric field (58 $\mathrm{V}_{\mathrm{RMS}}, 20 \mathrm{kHz}$, square waveform). Both photomicrographs show the same area of the slide; the right sections of both photomicrographs are within the ITO electrodes and thus respond to the applied field, whereas the left virginal region is outside of this area. 
employed in prototype scattering devices are - to the best of our knowledge - almost exclusively nitrile based materials. ${ }^{\mathbf{1 , 4 , 5 , 1 1 , 3 3 , 3 4}}$ While the nitro group offers reduced clearing points relative to those of the analogous nOCB compounds (Tables 1 and 2) these materials remain attractive due to their reduced switching voltage. This provides a fresh impetus to prepare not only new nitro-terminated materials (such as those incorporating bulky terminal substituents) but also to examine other highly polar functional groups such as $-\mathrm{SF}_{5}$ and $-\mathrm{SF}_{4} \mathrm{CF}_{3}$ as well as ortho fluorinated cyano- and nitro-biphenyls.

\section{Conclusions}

The 4-alkoxy-4'-nitrobiphenyls exhibit reduced transition temperatures and higher melting points than the analogous cyano terminated materials (nOCB series, Table 2). Small angle $\mathrm{X}$-ray scattering was used to demonstrate that the smectic phase exhibited by the 4 -alkoxy-4'-nitrobiphenyls is of the same subtype as the nOCB compounds, i.e. an interdigitated smectic $\mathrm{A}\left(\mathrm{SmA}_{D}\right)$. The smectic A phase of the nitro terminated material 9, when doped with $0.1 \mathrm{wt} \%$ hexadecylammonium perchlorate, can be switched between a scattering state and a clear state with a voltage of roughly half of that required for the analogous nitrile material 110CB. This suggests that other polar terminal groups may enjoy significant advantages over nitriles in terms of switching voltage when employed as hosts in scattering devices utilising the smectic A phase.

\section{Conflicts of interest}

There are no conflicts to declare.

\section{Acknowledgements}

The authors thank QinetiQ for funding an ICASE studentship for RJM. EPSRC grant EP/M020584/1 for the development of dyes for liquid crystal applications, EPSRC Platform Grant EP/ D055261/1, EPSRC grant EP/J007714/1 for the development of liquid crystals for displays and lastly EPSRC core capabilities grant EP/K039660/1. Raw data pertinent to this work is available on request from the University of York.

\section{References}

1 K. Li, M. Pivnenko, D. P. Chu, A. Cockburn and W. O'Neill, Liq. Cryst., 2016, 43, 735-749.

2 H. Y. Chen and J. S. Wu, J. Soc. Inf. Disp., 2010, 18, 415-420.

3 H. Y. Chen, R. Shao, E. Korblova, D. Walba, N. A. Clark and W. Lee, J. Soc. Inf. Disp., 2008, 16, 675-681.

4 D. J. Gardiner and H. J. Coles, J. Appl. Phys., 2006, 100, 124903.

5 D. J. Gardiner and H. J. Coles, J. Phys. D: Appl. Phys., 2006, 39, 4948-4955.

6 S. Khosla, K. K. Raina and H. J. Coles, Curr. Appl. Phys., 2003, 3, 135-140.

7 D. Coates, W. A. Crossland, J. H. Morrissy and B. Needham, J. Phys. D: Appl. Phys., 1978, 11, 2025-2034.
8 C. Tani, Appl. Phys. Lett., 1971, 19, 241-242.

9 Y. Lu, J. B. Guo, H. Wang and J. Wei, Adv. Condens. Matter Phys., 2012, DOI: 10.1155/2012/843264.

10 A. J. Leadbetter, J. C. Frost, J. P. Gaughan, G. W. Gray and A. Mosley, J. Phys., 1979, 40, 375-380.

11 R. J. Mandle, E. J. Davis, C. C. A. Voll, D. J. Lewis, S. J. Cowling and J. W. Goodby, J. Mater. Chem. C, 2015, 3, 2380-2388.

12 R. J. Mandle, E. J. Davis, J. P. Sarju, N. Stock, M. S. Cooke, S. A. Lobato, S. J. Cowling and J. W. Goodby, J. Mater. Chem. C, 2015, 3, 4333-4344.

13 J. Newton, H. Coles, P. Hodge and J. Hannington, J. Mater. Chem., 1994, 4, 869-874.

14 C. P. J. Schubert, C. Muller, A. Bogner, F. Giesselmann and R. P. Lemieux, Soft Matter, 2017, 13, 3307-3313.

15 M. Thompson, C. Carkner, N. J. Mosey, N. Kapernaum and R. P. Lemieux, Soft Matter, 2015, 11, 3860-3868.

16 K. M. Mulligan and R. P. Lemieux, Liq. Cryst., 2015, 42, 12291235.

17 M. Thompson, C. Carkner, A. Bailey, N. J. Mosey, N. Kapernaum and R. P. Lemieux, Liq. Cryst., 2014, 41, 1246-1260.

18 C. P. J. Schubert, A. Bogner, J. H. Porada, K. Ayub, T. Andrea, F. Giesselmann and R. P. Lemieux, J. Mater. Chem. C, 2014, 2, 4581-4589.

19 K. M. Mulligan, A. Bogner, Q. X. Song, C. P. J. Schubert, F. Giesselmann and R. P. Lemieux, J. Mater. Chem. C, 2014, 2, 8270-8276.

20 Q. X. Song, D. Nonnenmacher, F. Giesselmann and R. P. Lemieux, J. Mater. Chem. C, 2013, 1, 343-350.

21 Q. X. Song, A. Bogner, F. Giesselmann and R. P. Lemieux, Chem. Commun., 2013, 49, 8202-8204.

22 E. J. Davis, R. J. Mandle, B. K. Russell, P. Y. Foeller, M. S. Cook, S. J. Cowling and J. W. Goodby, Liq. Cryst., 2014, 41, 1635-1646.

23 I. Rupar, K. M. Mulligan, J. C. Roberts, D. Nonnenmacher, F. Giesselmann and R. P. Lemieux, J. Mater. Chem. C, 2013, 1, 3729-3735.

24 R. J. Mandle, S. J. Cowling, I. Sage, M. E. Colclough and J. W. Goodby, J. Phys. Chem. B, 2015, 119, 3273-3280.

25 B. Jones and F. Chapman, J. Chem. Soc., 1952, 1829-1832, DOI: $10.1039 /$ jr9520001829s.

26 M. J. Frisch, G. W. Trucks, H. B. Schlegel, G. E. Scuseria, M. A. Robb, J. R. Cheeseman, G. Scalmani, V. Barone, B. Mennucci, G. A. Petersson, H. Nakatsuji, M. Caricato, X. Li, H. P. Hratchian, A. F. Izmaylov, J. Bloino, G. Zheng, J. L. Sonnenberg, M. Hada, M. Ehara, K. Toyota, R. Fukuda, J. Hasegawa, M. Ishida, T. Nakajima, Y. Honda, O. Kitao, H. Nakai, T. Vreven, J. A. MoCntgomery Jr, J. E. Peralta, F. Ogliaro, M. J. Bearpark, J. Heyd, E. N. Brothers, K. N. Kudin, V. N. Staroverov, R. Kobayashi, J. Normand, K. Raghavachari, A. P. Rendell, J. C. Burant, S. S. Iyengar, J. Tomasi, M. Cossi, N. Rega, N. J. Millam, M. Klene, J. E. Knox, J. B. Cross, V. Bakken, C. Adamo, J. Jaramillo, R. Gomperts, R. E. Stratmann, O. Yazyev, A. J. Austin, R. Cammi, C. Pomelli, J. W. Ochterski, R. L. Martin, K. Morokuma, V. G. Zakrzewski, G. A. Voth, 
P. Salvador, J. J. Dannenberg, S. Dapprich, A. D. Daniels, Ö. Farkas, J. B. Foresman, J. V. Ortiz, J. Cioslowski and D. J. Fox, Gaussian 09, Revision E.01, 2009.

27 M. Tarini, P. Cignoni and C. Montani, IEEE Trans. Vis. Comput., 2006, 12, 1237-1244.

28 B. Jones and J. P. Sleight, J. Chem. Soc., 1954, 1775-1780, DOI: $10.1039 /$ jr9540001775.

29 M. Hird, A. J. Seed, K. J. Toyne, J. W. Goodby, G. W. Gray and D. G. Mcdonnell, J. Mater. Chem., 1993, 3, 851-859.

30 R. Faghih, W. Dwight, A. Vasudevan, J. Dinges, S. E. Conner, T. A. Esbenshade, Y. L. Bennani and A. A. Hancock, Bioorg. Med. Chem. Lett., 2002, 12, 3077-3079.

31 T. Itahara and H. Tamura, Mol. Cryst. Liq. Cryst., 2007, 474, 17-27.
32 A. Mouquinho, M. Saavedra, A. Maiau, K. Petrova, M. T. Barros, J. L. Figueirinhas and J. Sotomayor, Mol. Cryst. Liq. Cryst., 2011, 542, 132-140.

33 T. V. Clapp, W. A. Crossland, A. B. Davey, M. Grasmann, J. P. Hannington, R. K. King, M. Pivnenko, S. Robson and $\mathrm{H}$. Xu, Liquid crystal formulations and structures for smectic A optical devices, WO 8956548, 2015.

34 J. P. Hannington, T. V. Clapp, F. Nishida, R. K. King, O. Farooq, M. Grasmann, W. A. Crossland, H. J. Coles, A. B. Davey, H. Xu, O. Hadeler and M. Pivnenko, Oligosiloxane modified liquid crystal formulations and devices using same, US Pat. 8821992, 2014. 